\title{
IALL PROGRAM AT THE AECT CONVENTION IN DALLAS, TX. JANUARY 20-24, 1984
}

The following IALL presentations have been submitted for the 1984 AECT convention in Dallas. For times and locations check the AECT convention.

\section{Presentation \#1}

TITLE: Matching Computer Technology and Foreign Language Skills

Presentor(s):

Sue Otto

Associate Director

Language Media Center

University of lowa

Schaeffer Hall 125

lowa City, IA 52242

(319) 353-3190
James Pusack

Associate Professor \& Chair,

Department of German

University of lowa

Schaeffer Hall 103

lowa City, IA 52242

(319) $353-4937$

Description: A systematic overview will be presented of the way various computer-based modes may be applied to the basic skill areas of language teaching including vocabulary, pronunciation, speaking, listening, reading, writing, grammar, and culture. Currently available materials and long term potential will be discussed. Videotape and microcomputer examples will be demonstrated. Attention will also be focused on curriculum development. University of lowa projects in grammar CAl, reading comprehension, image retrieval via videodisc, and international computer controlled video will be highlighted.

\section{Presentation \#2}

TITLE: Media Resource Center Management in Higher Education: New Organizations for the times

Presentor(s):

Dr. Robin E. Lawrason, Director Media Learning Center

Temple University

Humanities HL 21

Philadelphia, PA 19122

(215) $787-8265$

Martha R. Richardson, Director

Learning Lab

Harvard University

Boylston Hall G-3

Cambridge, MA 02138

(617) 495-9402

Description: This session will review various new models of media organization based on recent re-organization at several institutions. Also discussed will be the problems, issues, and means of alleviating the potential conflicts between philosophies, missions, training, and the roles of the different professionals involved. 


\section{Presentation \#3}

TITLE: Human Perspectives in Learning Lab Design and Use: The Manufacturers Respond

Presentor: Dr. Reed Gilgen, Director

Laboratory for Recorded Instruction

University of Wisconsin

Madison, WI 53706

(608) 262-1408

Description: This season will feature a dialogue between lab users and manufacturers. The users will be encouraged to ask the manufacturers about resources available to assist in the design, use, and promotion of learning labs. The manufacturers will be given the opportunity to respond on how they are best able to assist potential users. Questions should focus on human perspectives rather than technical specifications.

International Association for Learning Laboratories

NALLD JOURNAL

New Advances in Learning Laboratory Development

Name MEMBERSHIP

APPLICATION

Title

$\square$ New Member

North American

U.S./Can/Mexico

$\square$ Renewal

All libraries +

Foreign air mall

Student

be sent:

Sustaining

Member

City ............ State ..... Zip

Return this form to:

NALLD JOURNAL Academic Publications Administration Building University of Louisville, KY 40292 


\section{CALL FOR PROPOSALS FOR CONFERENCE PROGRAMS}

Each year IALL sponsors presentations in conjunction with, but not limited to, the three major professional conferences: ACTFL, AECT, and the Northeast Conference. Papers on topics of interest to Learning Lab directors, as well as papers on the overall topic of mediated language instruction are being solicited for presentation at any appropriate professional conferences. Many IALL members are engaged in numerous projects that would be of interest to other media professionals. Please support your organization as well as your own professional growth by sharing your experience with your colleagues. The following schedule gives the dates for submission of proposals to two major conferences:

Association of College Teachers of Foreign Languages

Chicago, IL

November 22-24, 1984

Proposal deadline: January 10, 1984

Association for Educational Communications and Technology (AECT)

Anaheim, CA

January 25-27, 1984

Proposal deadline: May 1, 1984

Please send proposals to:

Dr. Robin Lawrason, Director

Media Learning Center

Humanities Building HL-21

Temple University

Philadelphia, PA 19122

215-787-8625

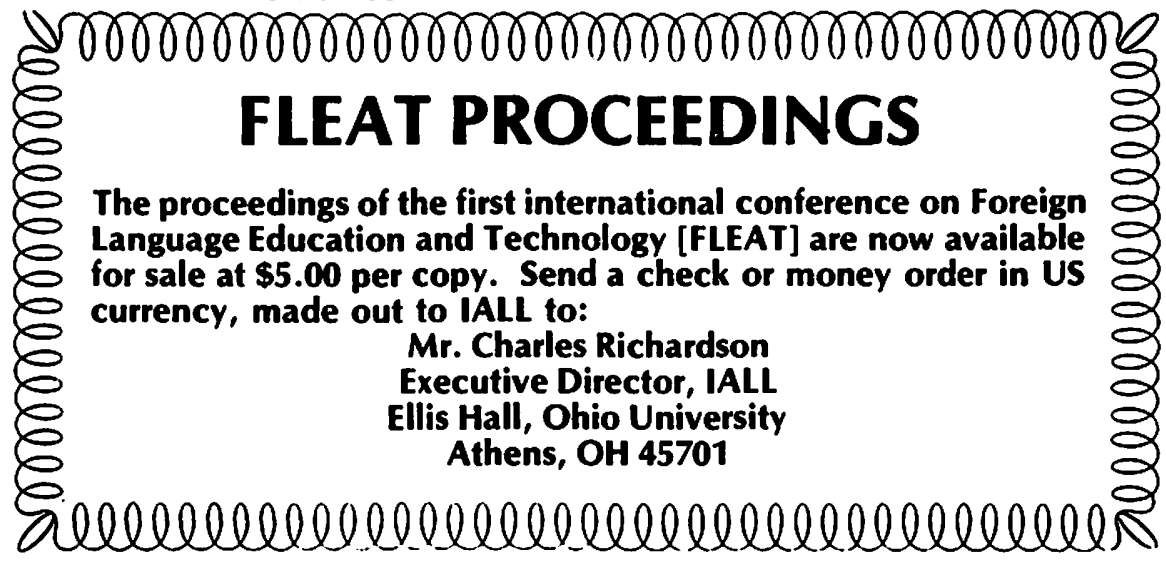




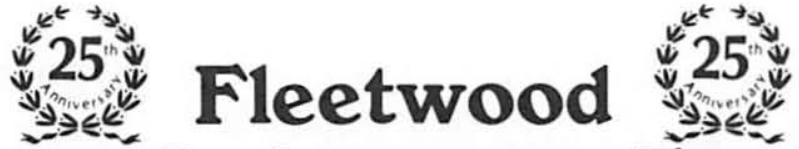 Language Laboratory Equipment}

An

Original

Language Lab

Manufacturer

Still Operating

Under Its Same

Name

\section{Retractable \\ Overhead \\ Headset \\ Storage \\ Systems}

Choice of up to 6 Lesson

Channels

for up to

64

Students

\section{WIRED-IN SYSTEMS}

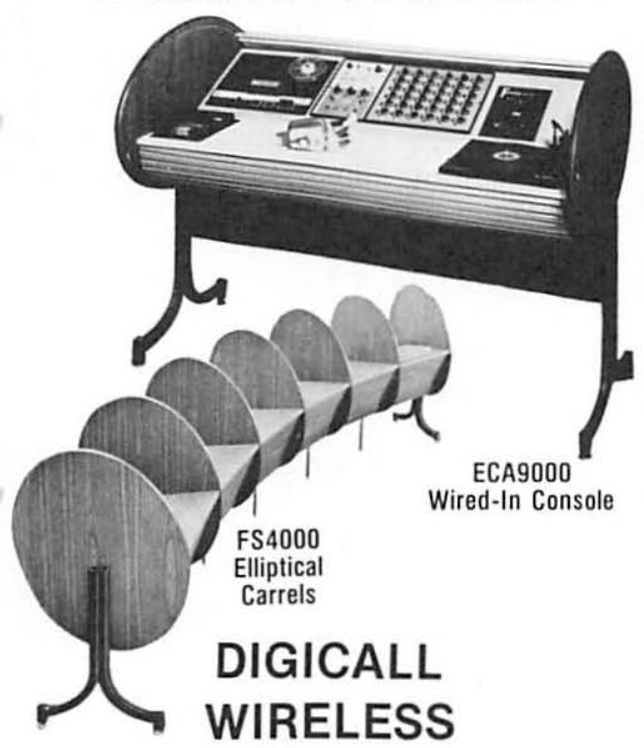

WITH MONITOR-INTERCOM

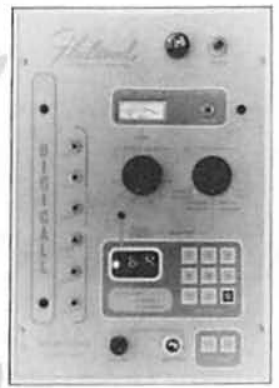

Console Control Center

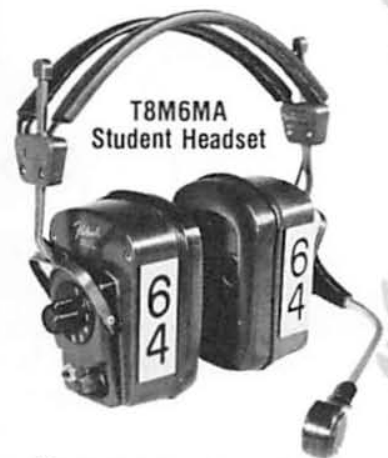

Choice

of Carrels

and

Student

Recorders
Will

Design

\& Build to

Meet Your

Specific

Teaching

Needs

Complete

Mobility Because

It's Wireless

No Student

Headset

Cords

Choice of

Three

Console Cabinets Including Mobile Console

Listen to lesson. Hear own response.

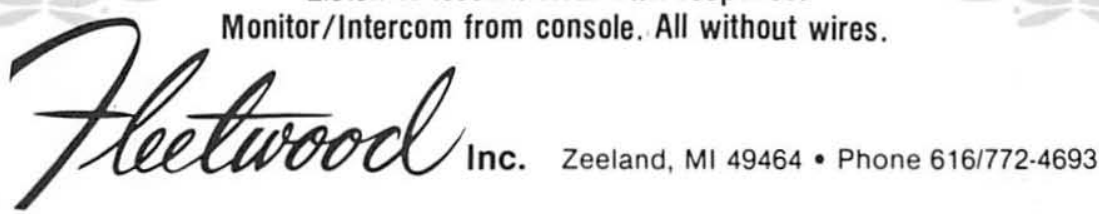

